\title{
Bioavailability of carotenoids
}

\author{
Jacqueline J.M. Castenmiller ${ }^{\mathrm{a}}$ and Clive E. West ${ }^{\mathrm{a}, \mathrm{b}}$ \\ ${ }^{a}$ Wageningen Agricultural University, Department of Human Nutrition, \\ P.O. Box 8129, 6700 EV Wageningen, The Netherlands \\ ${ }^{b}$ Rollins School of Public Health of Emory University, Department of \\ International Health, 1518 Clifton Road, NE, Atlanta GA 30322, USA
}

\begin{abstract}
Bioavailability can be defined as the proportion of a nutrient ingested which becomes available to the body for metabolic processes or the proportion of a nutrient being capable of being absorbed and available for use or storage or, more briefly, the proportion of a nutrient ingested that can be used. Results of studies carried out in Indonesia indicate that the bioavailability of provitamin A in dark-green leafy vegetables and carrots is extremely low. Purified carotene in oil was found to be more bioavailable than carotene from leafy vegetables and carrots. Carotenoids from fruits were found to be more bioavailable than those from darkgreen leafy vegetables and carrots. An algorithm of factors which influence bioavailability of carotenoids with the mnemonic 'SLAMANGHI' has been developed: Species of carotene; molecular Linkage; Amount of carotene consumed

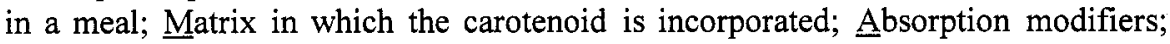
Nutrient status of the host; Genetic factors; Host related factors; and Interactions. Thus, the bioavailability of carotenoids is influenced by both extrinsic and intrinsic factors. Data should be collected to quantify each of these factors in order to develop a model to predict the bioavailability of carotenoids from different foods under a range of conditions in the host.
\end{abstract}

\section{INTRODUCTION}

Vitamin A activity can be obtained from two classes of compounds: retinoids (retinol and related compounds usually with 20 carbon atoms) and carotenoids ( $\beta, \beta$-carotene and related carotenoids usually with 40 carbon atoms). Of the 600 carotenoids produced by plants and lower organisms (refs. 1,2) about 50 have provitamin A activity because they can be converted into retinol in animals. Vitamin A deficiency has serious consequences, including changes to the eye (xerophthalmia); changes to other epithelial tissues; increased susceptibility to infection; increased rates of morbidity, especially from respiratory diseases; increased mortality; and nutritional anaemia (ref. 3). The control of vitamin A deficiency in the world is now given high priority by national governments and international agencies. Basically, there are four major approaches to controlling vitamin A deficiency, namely public health measures, particularly measles vaccination; supplementation and massive dosing; fortification or enrichment of foods with vitamin $A$ or $\beta, \beta$-carotene; and natural food approaches, such as the promotion of available foods with a high content of vitamin A and/or pro-vitamin A carotenoids. Of course, also a combination of these approaches can be used.

Apart from being precursors of retinol and retinoids, carotenoids have distinct functions of their own in humans and animals. Carotenoids have been postulated to play a protective role in heart disease (ref. 4) and cancer, especially cancer of epithelial tissues, although intervention studies have not borne this out (ref. 5). One of the problems of relating dietary intake of carotenoids to health status is that there is very little information on bioavailability of carotenoids. 


\section{DEFINITION OF BIOAVAILABILITY}

Bioavailability can be defined as the proportion of a nutrient ingested which becomes available to the body for metabolic processes (ref. 6) or the proportion of a nutrient being capable of being absorbed and available for use or storage or, more briefly, the proportion of a nutrient ingested that can be used (ref. 7). Bioavailability can also be defined as the proportion of a nutrient which is absorbed from a food relative to the absorption of a similar amount of the nutrient in pure form.

In order for a nutrient to be capable of being used, it must either be present in the diet in a form that can be transported across the mucosa or the ingested form must be capable of being transformed into a transportable form. In addition, the nutrient must be absorbed in a form that can be utilised in normal metabolism. Absorption of the fat-soluble carotenoids is impaired in any disease producing fat malabsorption (ref. 8). Conventionally, three phases constitute the process of absorption of exogenous fat and fat-soluble vitamins: intraluminal, mucosal, and delivery. The intraluminal phase includes chemical hydrolysis by lipolytic enzymes and the micellar solubilization of lipolytic products by bile acids. The mucosal phase comprises the diffusion of micelles through the unstirred water layer, passive diffusion across the microvillous membrane of the enterocyte, and the formation of lipid-carrying lipoproteins. The delivery phase involves the exocytosis of chylomicrons from the absorptive cells and their subsequent removal by lymphatic structures and the systemic circulation. The precise steps and factors involved in all phases of chylomicron synthesis are not yet known (ref. 9). Interference with the intraluminal phase results in maldigestion, while interference in either of the subsequent steps produces malabsorption.

Generally, less than one sixth of $\beta, \beta$-carotene is absorbed in humans (ref. 10) although Blomstrand and Werner (ref. 11) reported that one subject absorbed more than half of the $B, \beta$-carotene fed. Balance studies have indicated that between 50 and $75 \%$ of $\beta, \beta$-carotene could be absorbed (ref. 12) but such studies do not take into account possible breakdown in the large gut.

\section{RESULTS FROM STUDIES CARRIED OUT IN INDONESIA}

In a study on the carotenoid content of foods (ref. 13), a comparison was made between provitamin $\mathrm{A}$ data found in the Indonesian food composition table and the best data on the provitamin A content of foods currently available. As a result of this finding, the estimate for the provitamin A intake of pregnant women in Indonesia had to be reduced by at least $50 \%$. But, most likely, not only the amount of provitamin $\mathrm{A}$ in vegetables but also the bioavailability may provide an explanation for the observation that pregnant and lactating women had marginal vitamin A deficiency while consuming over twice the recommended daily allowance for vitamin $A$ as $\beta, \beta$-carotene.

For a study carried out in West Java, Indonesia, from September 1993 to January 1994, women were selected with low haemoglobin values and who were breastfeeding children aged 3-17 months (ref. 14). The women $(n=175)$ came from two villages and women from one village were assigned a stir-fried vegetable supplement and women from the other village received either an enriched or a control wafer for 12 weeks. The vegetable supplement contained similar amounts of $\beta, \beta$-carotene, iron, and folic acid, and slightly more fat than the enriched wafer. In the enriched-wafer group increases in serum retinol, breastmilk retinol, and serum $\beta, \beta$-carotene were observed. These changes differed significantly from those in the other two groups, suggesting that an additional portion of dark-green leafy vegetables daily does not improve vitamin $A$ status whereas a similar amount of $B, \beta$-carotene from a simpler matrix showed a strong improvement. The results indicate that the bioavailability of provitamin $\mathrm{A}$ in darkgreen leafy vegetables is extremely low.

Another intervention study was carried out in July-October 1995, again in West Java, to test the comparative effectiveness of provitamin A from dark-green leafy vegetables and carrots, yellow and orange fruits, and dietary retinol sources. For this study four groups ( $\mathrm{n}=53-60)$ of anaemic children (mean age 10 years) were selected who received two meals per day for 9 weeks (S. de Pee, C.E. West, D. Permaesih, Muhilal and J.G.A.J. Hautvast). The meals contained different amounts of retinol equivalents provided by different types of foods. Preliminary results from this study indicate that the increase in serum retinol levels was highest in the retinol-rich group and lowest in the control group 
while the response in the fruit group was higher than that in the vegetable group. Compared with the control group carotene-rich fruits increased serum $\beta, \beta$-carotene concentration four to five times more than the vegetables. Furthermore, carotene-rich foods increased the haemoglobin concentration of subjects significantly more than dark-green leafy vegetables. The consumption of dark-green leafy vegetables increased the serum $\beta, \beta$-carotene concentration, but the serum retinol concentration did not increase compared with the control group.

These results imply that the bioavailability of carotenoids from vegetables and fruits is lower than expected. Therefore, factors for converting dietary carotene content to retinol equivalents, being six for $\beta, \beta$-carotene and twelve for other provitamin A carotenoids (ref. 15), need to be reconsidered. The finding that $\beta, \beta$-carotene was better absorbed from fruits than from vegetables indicates that both the matrix of the food as well as the amount and nature of absorption modifiers are important determinants of carotene bioavailability.

\section{FACTORS AFFECTING BIOAVAILABILITY}

A number of factors are known from various studies to affect the bioavailability of carotenoids in humans. These have been incorporated into the mnemonic 'SLAMANGHI' (ref. 16) which include:

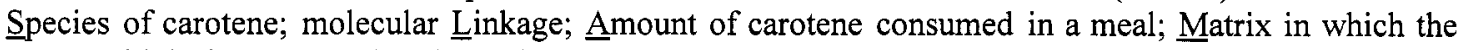
carotenoid is incorporated; Absorption modifiers; Nutrient status of the host; Genetic factors; Host related factors; and Interactions. A prediction of the bioavailability of carotenoids of different foods and under specified circumstances would thus be possible if each of these factors could be quantified.

\section{Species of carotenoids}

All carotenoids containing at least one unsubstituted $\beta$-ring and a polyene side-chain attached are potential precursors of vitamin $A$, with $\beta, \beta$-carotene showing the highest vitamin $A$ activity on a molar basis. A full list of trivial and corresponding semi-systematic names of naturally occurring carotenoids has been described (ref. 2) and updated (ref. 17). Up until recently it was difficult to study the metabolism of carotenoids because of the analytical problems involved. This was especially true for carotenoids other than (all-E)- $\beta, \beta$-carotene until separation of various carotenoids by high-performance liquid chromatography (HPLC) both in foods (ref. 18) and serum (ref. 19) became possible. By using chiral column HPLC, individual optical isomers of carotenoids can be resolved.

The bioavailability and provitamin A activity of the geometrical isomers differ and various studies suggest that individual isomers of $\beta, \beta$-carotene are absorbed from the intestine to a different extent. Pure (all-E)- $\beta, \beta$-carotene is isomerized by light and/or heat to generate a mixture which contains (13Z)- and $(9 Z)-\beta, \beta$-carotene as the main $(Z)$-isomers (ref. 20 ). The naturally occurring $\beta, \beta$-carotene in plant foods is generally the (all- $E$ )-isomer. As a provitamin A nutrient, the (all-E)-compound possesses the highest bioavailability relative to the (Z)-configurations in rats and presumably humans. The (9Z)- and (13Z)isomers have only $40-50 \%$ of vitamin A precursor activity of native $\beta, \beta$-carotene. The $(Z)$-isomeric composition increases with food processing particularly heating and the quantity formed appears related to the severity and extent of heat treatment. The predominant $(Z)$-isomers found in foods are the 13and 9-mono-(Z)-isomers. The widespread use of processed foods as a part of daily diets implies that the consumption of $(Z)-\beta, \beta$-carotene isomers is prevalent (ref. 21 ).

\section{Molecular linkage}

Some hydroxycarotenoids in common foods exist as esters, e.g. $\beta, \beta$-caroten-3-ol ( $\beta$-cryptoxanthin) in papaya, and need to be hydrolysed before being absorbed, but this process is probably not limiting. Hydroxycarotenoids also exist as glycosides in bacteria but, although not split in the human gut, are unlikely to form a significant part of the diet.

\section{Amount of carotenoids consumed in a meal}

B, $\varepsilon$-Carotene-3,3'diol (lutein) and $\beta, \beta$-carotene interact with each other during intestinal absorption, metabolism, and serum clearance, although individual responses can differ markedly (ref. 22). 
Administering $\beta, \beta$-carotene daily in three divided doses with meals raised the serum $\beta, \beta$-carotene concentration three times as much as did the same total dose administered once a day (ref. 23). Also, ordinary processing and cooking of vegetables can affect the metabolic response to a mixed meal.

\section{Matrix in which the carotenoid is incorporated}

$\beta, \beta$-Carotene in oil is absorbed far more readily than $\beta, \beta$-carotene from plant foods. For example, the plasma response to $\beta, \beta$-carotene in oil has been found to be about five times higher than the response to a similar amount of $\beta, \beta$-carotene in carrots (refs. 24,25). The bioavailability of carotenoids in dark-green leafy vegetables such as spinach (Spinacea oleracea), root vegetables such as carrots (Daucus carota), and fruits such as mango (Mangifera indica) and papaya (Carica papaya) probably partly depends on the matrix in which the carotenoid is located in the unprocessed product. Results of the studies carried out in Indonesia discussed above support this idea. Processing methods can produce considerable isomerization to (9Z)- and (13Z)-isomers. The effect of processing on the bioavailability of carotenoids has been studied for a number of fruits and vegetables. Studies have shown that cooking increases the bioavailability of carotenes possibly because of the softening or disruption of plant cell walls and the disruption of carotenoid-protein complexes (ref. 26). Green vegetables showed an average increase in lutein response in serum of $24 \%$ and in $\beta, \beta$-carotene levels of $38 \%$ (ref. 27). Fine grinding of food achieved the same effect (ref. 28).

\section{Absorption modifiers}

Several studies have demonstrated the effect of dietary fat concentration on the absorption of $\beta, \beta$ carotene. Individuals placed on a high-fat diet showed significant increases in plasma $\beta, \beta$-carotene compared with those placed on a low-fat diet (ref. 29). The increase in plasma $\beta, \beta$-carotene in humans is significantly reduced by dietary pectin (ref. 30 ) and results from studies with chickens would suggest that the extent of methyl esterification of the pectin is important in determining the extent of inhibition of absorption (ref. 31). Ethanol interacts with retinol and there is evidence that ethanol interferes with the conversion of $\beta, \beta$-carotene to vitamin $A$ (ref. 32). Another important factor that may decrease $\beta, \beta-$ carotene bioavailability is the interaction with drugs such as sulphonamides and aspirin in the gastrointestinal tract.

\section{Nutrient status of the host}

The absorption of retinol and the conversion of pro-vitamin A carotenoids to retinol, but not the absorption of carotenoids per se, would appear to depend on vitamin A status. The absorption of $\beta, \beta-$ carotene and total carotenes in children underweight but not acutely malnourished was found to be similar to that in healthy adults (ref. 12). There seems to be an absence of data on severely malnourished children but it would be expected, especially in children suffering from kwashiorkor, that the absorption of carotene would be reduced. Retinol deficiency can arise despite a plentiful supply of retinol (or carotene) when protein deficiency limits the production of the carotene-converting enzyme, carotenoid dioxygenase (ref. 33). It may well be that the bioconversion is also inhibited when the zinc status of the host is low. In addition, protein and zinc deficiency reduce the synthesis of retinol-binding protein thus impairing the delivery phase of absorption.

\section{Genetic factors}

The absorption of carotenoids, or fat-soluble vitamins in general, is impaired in any disease producing fat malabsorption. Defects in the mucosal phase of absorption ('malabsorption') are seen in conditions of fat malabsorption such as non-tropical sprue (ref. 34) and cystic fibrosis patients (ref. 35). The cat and recessive white canary (ref. 36) do not absorb $\beta, \beta$-carotene from the gut.

\section{$\underline{\underline{\text { Host related factors }}}$}

In the studies carried out in Indonesia, discussed above, the serum $\beta, \beta$-carotene concentration showed a large within-person coefficient of variation (127\%) probably due to differences in response to ingested $\beta, \beta$-carotene (S. de Pee, Y. Yuniar, C.E. West and Muhilal, submitted for publication). Several other 
studies reported a large variability in response to supplementation with oral $\beta, ß$-carotene and concluded that the best predictor of the response is the initial plasma $\beta, \beta$-carotene concentration (refs. 37,38).

For several diet and lifestyle factors, effects have been reported on the serum $\beta, \beta$-carotene concentration. Lower serum $\beta, \beta$-carotene concentration is associated with: male gender, smoking, younger age, lower non-high-density lipoprotein cholesterol, greater ethanol consumption, higher body mass index, and higher plasma triglyceride (refs. 39-43). These factors are probably not directly related to intraluminal or mucosal phases of carotene absorption but to differences in the delivery phase of absorption or tissue metabolism. Nonsmokers, women, and leaner subjects had larger increases in plasma concentrations following oral $\beta, \beta$-carotene supplementation (ref. 37).

The effectiveness of ten weeks of moderate dose ( $30 \mathrm{mg} /$ day) of $\beta, \beta$-carotene on plasma and skin $B, \beta-$ carotene levels during twelve days of time- and intensity-controlled sunlight exposure at sea level was evaluated. It was concluded that sunlight influenced the $\beta, \beta$-carotene and $\alpha$-tocopherol content of blood and tissues (ref. 44). Although absorption of carotene has not been found to be reduced in the presence of intestinal infestation, infections including acute respiratory infections do reduce absorption as measured by serum carotenoid levels (refs. 12,45). This is possibly because of the effect of fever in making the intestinal wall more 'leaky' as demonstrated by the loss of serum albumin into the lumen. There is no conclusive evidence that intestinal parasites interfere with carotene absorption but this is assumed because of the known effect of parasites on fat absorption generally.

\section{Interactions between the factors}

The individual factors discussed above almost certainly exert their effects in concert. Such multiple effects may be additive but there is no reason to believe that this is always the case and interactions may exist. For example, the effect of parasites on carotenoid bioavailability may be far greater when carotenoids are in dark-green leafy vegetables than when the carotenoids are dissolved in oil. However, at this stage, no quantitative data are available.

\section{CONCLUSION}

It is now apparent that the bioavailability of carotenoids plays an important role in determining the effectiveness of carotenoids in improving vitamin A and antioxidant status. Although the various factors which may play a role have been teased apart and incorporated in the mnemonic 'SLAMANGHI', there is really very little information about their relative contribution. Up until now, work in this area has been hampered by the lack of suitable techniques. It is hoped that with improved HPLC techniques for separating carotenoids, the availability of techniques for labelling carotenoids with stable isotopes, and the ability to measure the degree of enrichment of stable isotopes in carotenoids, much progress will be made in the near future. However, good experimental design and careful interpretation of the data will be essential in the pursuit of the goals.

\section{REFERENCES}

1. G. Britton, S. Liaaen-Jensen and H. Pfander. In Carotenoids. Volume IA: Isolation and analysis (G. Britton, S. LiaaenJensen and H. Pfander, eds), pp. 13-26. Birkhäuser Verlag, Basel (1995).

2. H. Pfander H (ed.). Key to carotenoids, 2nd ed. Birkhäuser Verlag, Basel (1987).

3. C.E. West. In Introduction to human nutrition (J. Mann and A.S. Truswell, eds). Oxford University Press, Oxford (in press).

4. A.F.M. Kardinaal, F.J. Kok, J. Ringstad, J. Gomez-Aracena, V.P. Mazaev, L. Kohlmeier, B.C. Martin, A. Varo, J.D. Kark, M. Delgado-Rodriguez, R.A. Riemersma, P. van 't Veer, J.K. Huttunen and J.M. Martin-Moreno. Lancet 342, 1379-1384 (1993).

5. The alpha-tocopherol, beta-carotene cancer prevention study group. N. Engl. J. Med. 330, 1029-1035 (1994).

6. R. Macrae, R.K. Robinson and M.J. Saddler. Encyclopedia of food science, food technology and nutrition. Academic Press, London (1993).

7. A.E. Bender. In Nutrient cvailability: chemical and biological aspects (D.A.T. Southgate, I.T. Johnson and G.R. Fenwick, eds), pp. 3-9. The Royal Society of Chemistry, Cambridge (1989).

8. W.G. Linscheer and A.J. Vergroesen. In Modern nutrition in health and disease, 8th ed. (M.E. Shils, J.A. Olson and M. Shike, eds.), pp. 47-88. Lea \& Febiger, Philadelphia (1994).

9. E. Levy. Can. J. Physiol. Pharmacol. 70, 413-419 (1992),

10. D.S. Goodman, R. Blomstrand, B. Werner, H.S. Huang and T. Shiratori. J. Clin. Invest. 45, 1615-1623 (1966). 
11. R. Blomstrand and B. Werner. Scand. J. Clin. Lab. Invest. 19, 339-345 (1967).

12. V.R. Lala and V. Reddy. Am. J. Clin. Nutr. 23, 110-113 (1970).

13. C.E. West and E.J. Poortvliet. The carotenoid content of foods with special reference to developing countries. International Science and Technology Institute, Vitamin A Field Support Project (VITAL), Arlington, Virginia (1993).

14. S. de Pee, C.E. West, Muhilal, D. Karyadi and J.G.A.J. Hautvast. Lancet 346, 75-81 (1995).

15. FAO/WHO. Requirements of vitamin A, folate and vitamin $B_{12}$. FAO, Rome (1988).

16. S. de Pee and C.E. West. Eur. J. Clin. Nutr. 50, Suppl. 3, S38-S53 (1996).

17. D. Kull and H. Pfander. In Carotenoids. Volume IA: Isolation and analysis (G. Britton, S. Liaaen-Jensen and H. Pfander, eds), pp. 295-317. Birkhäuser Verlag, Basel (1995).

18. M.S. Micozzi, G.R. Beecher, P.R. Taylor and F. Khachik. J. Natl. Cancer Inst. 82, 282-285 (1990).

19. D.W. Nierenberg and S.L. Nann. Am. J. Clin. Nutr. 56, 417-426 (1992).

20. J. Schierle, W. Härdi, N. Faccin, I. Bühler and W. Schüep. In Carotenoids. Volume IA: Isolation and analysis (G. Britton, S. Liaaen-Jensen and H. Pfander, eds), pp. 265-272. Birkhäuser Verlag, Basel (1995).

21. S.J. Schwartz and G.L. Catignani. In Nutrient availability: chemical and biological aspects (D.A.T. Southgate, I.T. Johnson and G.R. Fenwick, eds), pp. 80-82. The Royal Society of Chemistry, Cambridge (1989).

22. D. Kostic, W.S. White and J.A. Olson. Am. J. Clin. Nutr. 62, 604-610 (1995).

23. M.R. Prince and J.K. Frisoli. Am. J. Clin. Nutr. 57, 175-181 (1993).

24. E.D. Brown, M.S. Micozzi, N.E. Craft, J.G. Bieri, G. Beecher, B.K. Edwards, A. Rose, P.R. Taylor and J.C. Smith, Jr. Am. J. Clin. Nutr. 49, 1258-1265 (1989).

25. M.S. Micozzi, E.D. Brown, B.K. Edwards, J.G. Bieri, P.R. Taylor, F. Khachik, G.R. Beecher and J.C. Smith, Jr. Am. J. Clin. Nutr. 55, 1120-1125 (1992).

26. J.W. Erdman, C.L. Poor and J.M. Dietz. J. Agric. Food Chem. 42, 214-221 (1988).

27. D.J. Hart and K.J. Scott. Food Chem. 54, 101-111 (1995).

28. L. Hussein and M. El-Tohamy. Int. J. Vit. Nutr. Res. 60, 229-235 (1990).

29. N.V. Dimitrov, C. Meyer, E. Ullrey, W. Chenoweth, A. Michelakis, W. Malone, C. Boone and G. Fink. Am. J. Clin. Nutr. 48, 298.304 (1988).

30. C.L. Rock and M.E. Swendseid. Am. J. Clin. Nutr. 55, 96-99 (1992).

31. J.W. Erdman, G.J. Fahey, Jr and C.B. White. J. Nutr. 116, 2415-2423 (1986)

32. M.A. Leo, C.I. Kim, N. Lowe and C.S. Lieber. Hepatol. 15, 883-891 (1992).

33. A. Gronowska-Senger and G. Wolf. J. Nutr. 100, 300-308 (1970).

34. W.B. Evans and E.E. Wollaeger. Am. J. Dig. Dis. 11, 594-606 (1966).

35. D.R. James, G. Owen, I.A. Campbell and M.C. Goodchild. Gut 33, 707-710 (1992).

36. G.M. Dorrestein and J. Schrijver. Tijdschr. Diergeneeskd. 107, 795-799 (1982).

37. D.W. Nierenberg, T.A. Stukel, J.A. Baron, B.J. Dain, E.R. Greenberg, Skin Cancer Prevention Study. Am. J. Clin. Nutr. 53, 1443-1449 (1991).

38. D. Albanes, J. Virtamo, M. Rautalahti, J. Haukka, J. Palmgren, C.G. Gref and O.P Heinonen. Eur. J. Clin. Nutr. 46, 15-24 (1992)

39. S. Todd, M. Woodward and C. Bolton-Smith. J. Clin. Epidemiol. 48, 307-316 (1995).

40. W.E. Brady, J.A. Mares-Perlman, P. Bowen and M. Stacewicz-Sapuntzakis. J. Nutr. 126, 129-137 (1996).

41. K.J. Scott, D.I. Thurnham, D.J. Hart, S.A. Bingham and K. Day. Br. J. Nutr. 75, 409-418 (1996).

42. B. Herbeth, Y. Spyckerelle and J-P. Deschamps. Am. J. Clin. Nutr. 54, 884-889 (1991)

43. L.A. Kaplan, E.A. Stein, W.C. Willett, M.J. Stampfer and W.S. Strijker. Clin. Physiol. Biochem. 5, 297-304 (1987).

44. H.K. Biesalski, C. Hemmes, W. Hopfenmuller, C. Schmid and H.P.M. Gollnick. Free Radic. Res. 24, $215-224$ (1996).

45. W. Heymann. Am. J. Dis. Child 51, 273 (1936). 